\title{
Survey on Water-saving Agricultural Internet of Things based on Wireless Sensor Network
}

\author{
Zenglin Zhang, Xiaoqing $\mathrm{Yu}^{*}$, Pute $\mathrm{Wu}$ and Wengting Han \\ 1.Northwest A \& F University, Shaanxi, Yangling, 712100, China \\ 2.Research Institute of Water-saving Agriculture of Arid Regions of China, \\ Shaanxi, Yangling, 712100, China \\ E-mail: zhangzenglin115@gmail.com; yuxiaoqing115@gmail.comb; \\ hxqyu@sina.cn;wentinghan200@126.com
}

\begin{abstract}
Wireless Underground Sensor Networks (WUSN) have the potential to impact a wide variety of novel applications including intelligent irrigation, soil information monitoring, etc, the internet of tings for water-saving agriculture. WUSN consist of wireless devices that operate below the ground surface. These devices are buried completely under dense soil. The main difference between WUSN and the terrestrial wireless sensor network is the communication medium. This work provides an extensive overview of the research and application situations in agricultural internet of things for WUSN. The water-saving agricultural internet of things based on WUSN architecture is developed. Here, the main research for the underground communication channel including methods for predicting signal losses in an underground link. Based on the test model, research tests and results are discussed.
\end{abstract}

Keywords: Internet of things, Wireless sensor networks, Agriculture, Sensor nodes

\section{Introduction}

Water-saving agriculture can improve the effectiveness of water, is the system engineering of water, soil, crop resources comprehensive utilization. Informatization is the important and decisive link in water-saving agriculture, its main content includes perception, processing and integrated application, of the environment information, etc. With the development of modern science and technology, the study categories and industry of the water saving agriculture is not only widen, but it also provides advanced measures for modern water-saving agriculture and development of water-saving agricultural informatization [1,2]. Water-saving agriculture internet of things system is established based on wireless sensor network technology, the perception, processing, integration, decision-making and control application of information are conducted, which is the key and the main research contents of realization of water-saving agriculture and informatization, and is also the more mature technology in the field of water-saving agriculture application.

Internet of things is called the world's third wave of information industry after computer and the network, is the important component of a new generation information technology. The basic level and the development direction is internet of things system based on wireless sensor network structure [3]. Attention to the wireless sensor network is increasing in academic and industry area, the United States, the European Union and other countries are researching and exploring expensively internet of things based on wireless sensors, our country also is paying attention to the research and application of internet of things. At present, the development of the wireless sensor network technology is no longer limited to the ground [4-6], wireless underground sensor network (Wireless 
Underground Sensor Networks, WUSN) has become a new research aspect and development direction.

\section{Existing Wireless Sensor Networks Techniques}

\subsection{The Research and Application Situation of WSN}

Internationally, the European Union, the United States, Japan and other countries have paid attention to the internet of things project, and they have already did a lot of development research and application. At the burke branch university of California, the method of the sensor position was reconstructed using network connectivity, sensor data coding mode based on the correlation, the method of track mobile object route was reconstructed using sparse sensor network, the continuous flow visualization methods of sensor network changes with time, the general solution of effective communication mechanism when the system level was allowed to optimized, geographical Hash table method of distributed storage of sensor network data, certain of distributed algorithm nodes location in the sensor network, etc, were presented, and the operating system TinyOS was developed specially used in wireless sensor network.

At the Los Angeles branch University of California, a wireless sensor network and a wireless sensor network simulation environment were developed. In order to investigate all problems of the sensor network, they put forward the distributed system technology of the low-level communication did not depend on the network topology structure, the software structure of named data supporting for many applications sensor networks and the data processing in the net, level system structure of the transform from initial perception to senior data flow, the solution of sensor network time synchronization, design problem and solving methods of the self-organization sensor network and new multipath modes, etc.

The university of southern California put forward method of the mobile sensor were deployed in unfamiliar environment, monitoring structure of the sensor network, calculation method of accumulation function and tree structure algorithm of the save energy, etc. Stanford University put forward dual space method of event tracking and sensor resource management in sensor networks and closed loop control system framework constituted of wireless sensors and controls. Massachusetts institute of technology start to research ultra low energy wireless sensor network, trying to solve the problem of methodology and technology of low energy wireless sensor system [7-9]. At present, hardware has more mature samples in wireless sensor network research at overseas. There are many breakthroughs in aspect of the network algorithms.

In our country, research and application still is in the start level in the fields, some scientific research institution and universities including Tsinghua University, Shenyang institute of automation Chinese academy of sciences, Harbin institute of university have developed research in aspect of the sensor network, such as the hardware design of wireless sensor node, the operating system, network routing technology, saving energy technology, covering control technology. The low power consumption, low cost, high performance wireless network standard IEEE802.15.4 made by IEEE, the corresponding ZigBee standards launched by ZigBee alliance and the emergence of the wireless intellectual transmitter interface standard IEEE 145.1.5, which has brought an unprecedented opportunity for China to research and develop wireless sensor network technology with independent intellectual property rights.

\subsection{The Research Situation of WUSN}

Wireless underground sensor network is a new type of sensor network system. Underground sensor nodes buried in the different depth of the underground communicate 
using electromagnetic wave to form the three dimensional wireless network of the fixed structure, as shown in Figure 1. Different from the traditional underground surveillance method, there is not need cable to connect wireless underground sensor network node with the ground equipment, so as to avoid the damage of equipment and lines caused by ground vehicles or mechanical, while improve the flexibility of the nodes deployed and the concealment of the network. The main application of wireless underground sensor network includes: environmental monitoring of the water-saving agriculture, safety detection of mine, quality monitoring of underground facilities, navigation of ground vehicle, intelligent mines, etc [5].

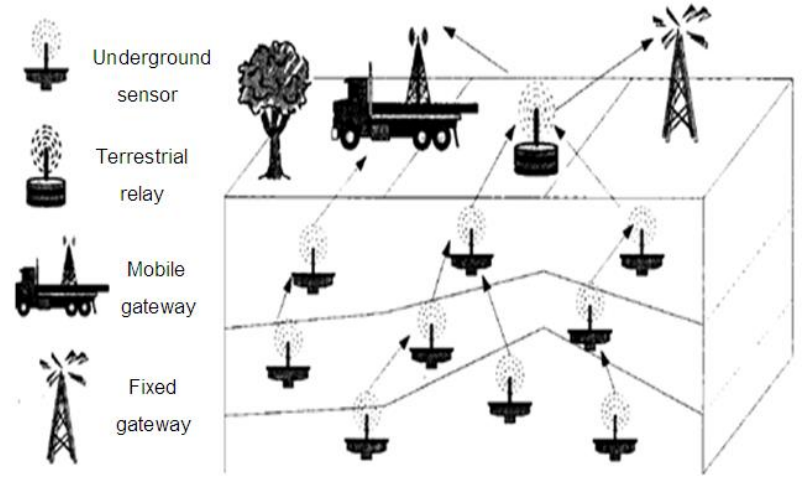

\section{Figure 1. Wireless Underground Sensor Network Architecture}

Most wireless sensor network adopt the two dimensional construction, cannot completely meet the needs of practical application. In the real world, there are massive applications of three dimensional wireless sensor networks, such as space, underwater and the underground sensors network system. However, due to complexity of solving the problem the three dimensional space, most research achievements of the existing two dimensional wireless sensor network cannot directly applied in three dimensional wireless sensor network. The development of three dimensional wireless sensor networks requires the new theory and method.

In some literatures, the name of the "underground wireless sensor network" was mentioned. The author puts forward use "underground wireless sensor network" to monitor the conditions of the underground coal mine, in order to strengthen security of mining area and ensure life safety of miners. But it is need to be aware that the concept of "underground wireless sensor network" in these literatures is totally different from the concept of "wireless underground sensor network" in this thesis stated. The designs of the sensor network in the literature are arranged in the tunnel of the coal mine, although coal mine is located in the underground, tunnel is still full of air, the sensor network nodes communicate each other still through the air. There has the essential difference from the style of "wireless underground sensor network" communication through the soil.

\subsection{Communication Characteristics of WUSN}

Currently, there are not definite theory and research achievements about wireless electromagnetic wave propagation in the underground soil, only limited to model research and simulation of parameters.

N.Elkmann imagine place sensors in the sewers for collection of underground water information, which will be used for Europe residential water flow management system in the next few years will, but in the literature, only the structure design of system is put forward, does not address the specific technical details of the signal through soil [10]; J.F.Mastarone put forward use sensors to build underground pipeline monitor system. In 
the literature, the author modified covers for pore antenna to make the underground sensor node communicate with the ground data collection equipment through its radiation function. This sort of communication does not involve soil medium, complete different from and wireless underground sensor network in the present study [11]; D.J.Daniels gave the whole introduced of the basic laws of surface penetrate radar technology. This paper presents the attenuation constants and dielectric constant form of several substances including soil in the following of $100 \mathrm{MHz}$ [12]; T.W.Miller described soil condition caused bigger effect on surface penetrate radar detection mineral [13]; T.R.Weldon observed the transmission process of electromagnetic wave through underground transmission line. The author used the microwave circuit analysis method to establish model, the frequency range is $1 \mathrm{GHz}$ to $2 \mathrm{GHz}$ [14].

Research work of the wireless underground sensor network in water-saving agriculture existing research problem is just beginning. The direction is a good opportunity for writing of new field and new chapter, achievement also very few, most are some consider ideas based on application, its specific design and key technology research are a challenging job.

\section{The Main Problems of the Research}

\subsection{Research of the WUSN Communication Characteristics}

WUSN node is buried in certain depth of the soil, propagation of node wireless electromagnetic wave in the soil has two ways, one is directly penetrate soil to the ground, and the other is the transmission pattern of the communication between WUSN nodes each other. Through modeling, design and test of the WUSN node, this paper need to study the characteristics relationship among soil parameters information, node buried depth, the signal frequency and attenuation in the two the transmission process, and then get applied conclusion, which lays the foundation for development of wireless underground sensor networks system. The structure of the WUSN node is shown in Figure 2, the main testing model is shown in Figure 3.

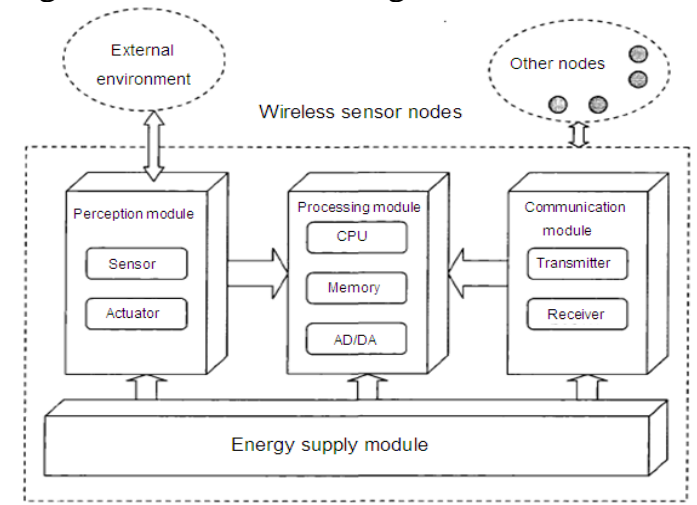

Figure 2. Wireless Underground Sensor Network Node Architecture 


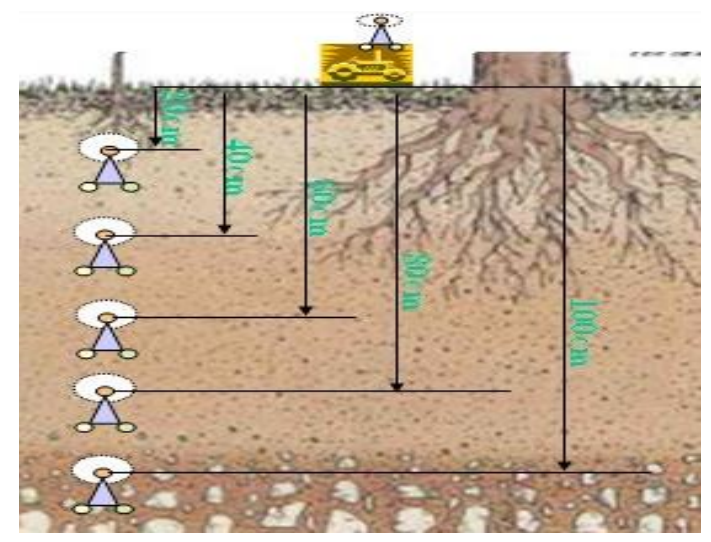

Figure 3. The Main Test Model

\subsection{The Research of Water-saving Agriculture WUSN System}

In WUSN, sensor nodes are deployed in the soil, the method of deploy is very different from the terrestrial wireless sensor network. Relative to the terrestrial wireless sensor network, WUSN has the following characteristics: First of all, the soil has great attenuation function to the electromagnetic wave, so the network communication quality, namely connectivity problem must be considered when the underground sensors network is built. Second, underground communication status are affected by soil composition, the signal frequency, node buried depth and volumetric water content factors, so the impact of these factors should be fully considered when sensors are placed [15-18]. Moreover, roots, stone etc larger obstacles existing in the soil have a lot of influence to the spread of electromagnetic wave. In addition, soil particle is not even, which also make the electromagnetic wave propagation in the uneven direction, besides the reflection action of the ground has the different influence on sensor node of the different buried depth.

Based on the above the main characteristics, the main research development flow chart of the topological model as shown in Figure 4 in the research and development of WUSN system; WUSN communication characteristics and communication channel test schemes are shown in Figure 5.

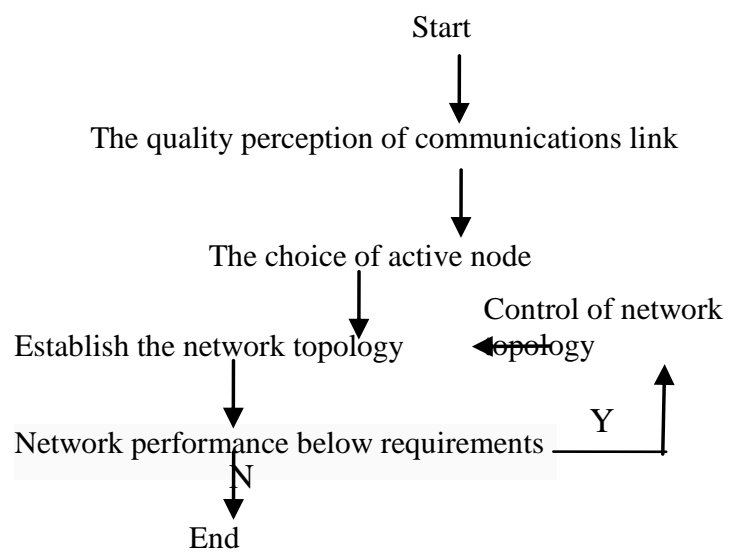

Figure 4. WUSN Topology Scheme Flowchart 


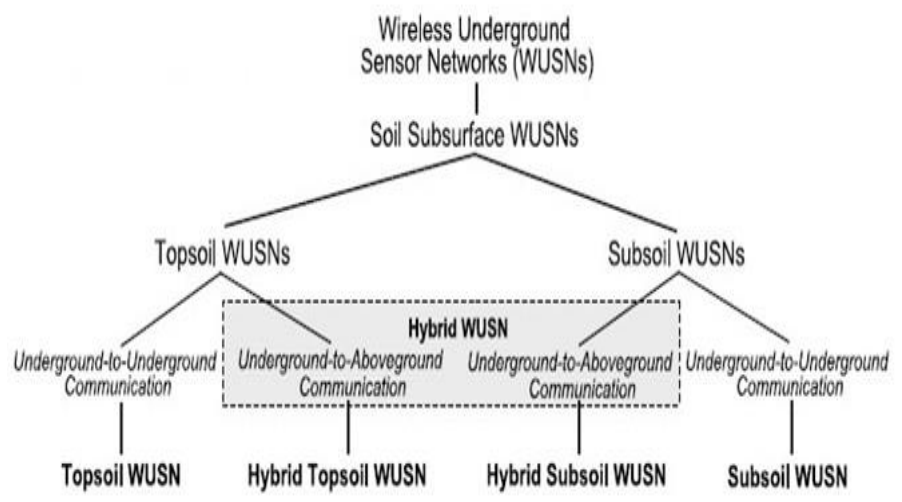

Figure 5. Scheme of the WUSN Communication Structure

The underground sensors network, the gateway and distal server communication system, the channel of underground nodes and gateway and regional communication solution are set up, the main research contents of WUSN design can be divided into three layers from bottom to up: the communication and network, management and basic services and application system, as shown in Figure 6.

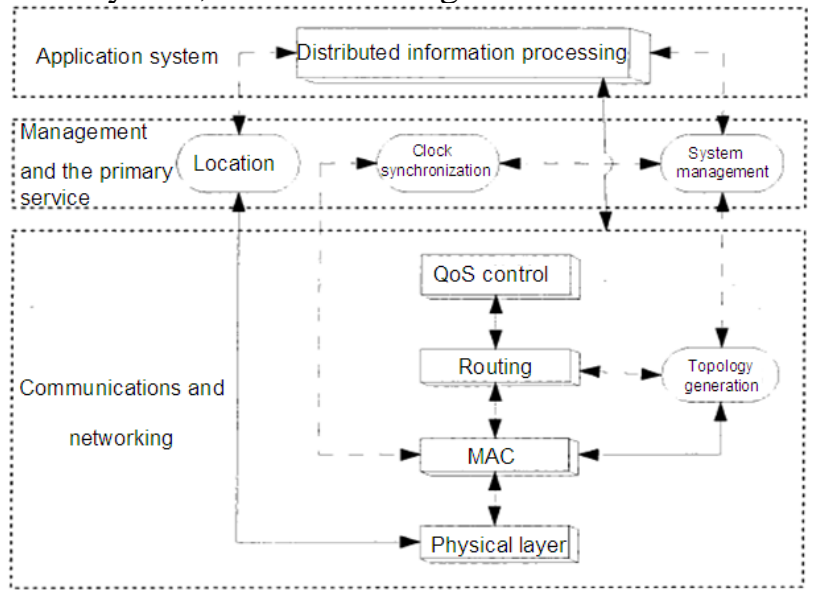

Figure 6. WUSN Architecture

\subsection{Study of Water-saving Agriculture Internet of Things}

The hierarchical structure of the internet of things can be divided into four layers from bottom to up: the sensor network layer, access network layer, middle ware layer and the application layer. The sensor network that is in the bottom layer form the network of data acquisition and control link soil environmental parameters sensor together, the schematic diagram of the overall structure is shown in Figure 7.

First of all, underground sensors collect soil environmental information in the lowest layer, then, this information are transmitted to the upper layer network space through sink node or base station of WUSN; Secondly, the data get access to the core network through the Bridges, gateway, routing and other network equipment after fused in the network layer (pretreatment); Then, data transmitted are stored in the corresponding server and are located position by locating model or algorithm in the middle ware layer; Finally, on the one hand, locating results are presented to the administrator in the application layer, on the other hand, they are feed backed to the WUSN system in the bottom of the networking 
according to crops water requirements to realize the corresponding irrigation control. This topic focus research and construction of WUSN system, based on this, the study is carried about the application of water-saving agriculture internet of things system and WUSN system based on the WUSN in other industries.

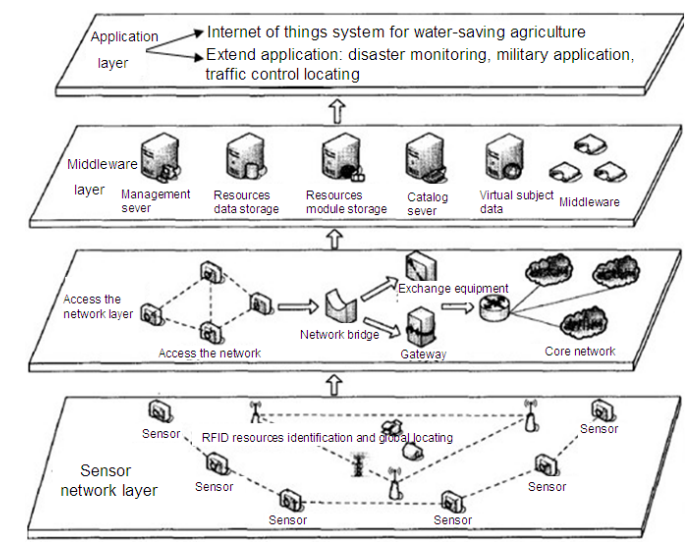

Figure 7. Water-saving Agricultural Internet of Things Structure based on WUSN

\section{Experiment Setup of WUSN}

\subsection{Test Method}

When wireless underground sensor network nodes get farmland information, reflection, scattering and diffraction may exist simultaneously in the process of wireless electromagnetic wave transmission in soil and interface between soil and air.

$\mathrm{RF}$ frequency is the core of electromagnetic signals is influenced. In addition, agricultural environment dynamic changes constantly as seasonal variation, soil water content will cause great path loss to the radio signal propagation. In order to path loss minimum when underground sensor nodes are deployed, it is necessary to find a proper depth, which guarantee deployment of sensor nodes is the most economic, signal paths loss is minimum, can transmission effectively.

In the trial, we assume the sand particle percent as $50 \%$, the silt percent as $35 \%$, the clay percent as $15 \%$, the bulk density as $1.5 \mathrm{~g} / \mathrm{cm} 3$, and the solid soil particle density as $2.6 / \mathrm{cm} 3$ unless otherwise noted. According to three different frequencies of RF modules nRF905, the attenuation of signal strength is measured in different soil volumetric water content VWC (VWC were taken as 5\%, 10\%, 15\%, 20\% and 25\%). Meanwhile, the path loss is measured in different depth h WUSN node deployed (h were taken as $0.2 \mathrm{~m}, 0.4 \mathrm{~m}$, $0.6 \mathrm{~m}, 0.8 \mathrm{~m}, 1 \mathrm{~m}, 1.2 \mathrm{~m}, 1.4 \mathrm{~m}, 1.6 \mathrm{~m}, 1.8 \mathrm{~m}$ and $2 \mathrm{~m}$ ) is under the same frequency.

\subsection{Test Analysis}

Path loss is the difference in value between real received signal strength and source signal strength level, namely the signal attenuation extent, it reflects directly efficiency of wireless electromagnetic signal transmission. Figure 8 describes the path loss of the wireless signals is caused by soil volumetric water content change in different frequencies. Figure 9 reflects the relationship between WUSN nodes deployed depth and the path loss under $433 \mathrm{MHz}$ RF frequencies. 


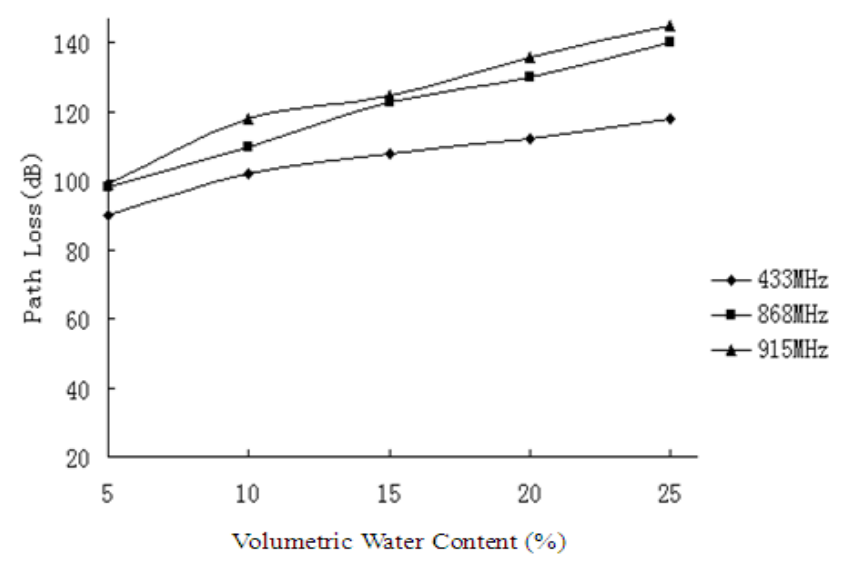

Figure 8. The Relationship of Path Loss, Frequency and Water Content

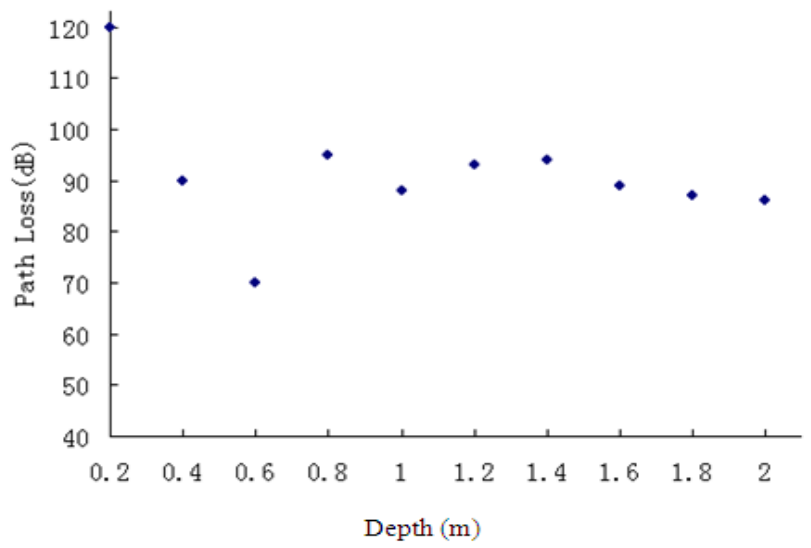

Figure 9. The Relationship between Path Loss and Depth

\section{Conclusions}

(1) According to the application requirement of farmland environmental information, wireless underground sensor network technology is researched. Underground sensor node and sink node are developed combined with embedded processors, which realized realtime dynamic collection, transmission, store and display for the farmland soil information parameter. Nodes satisfy requirements of low power consumption, low cost, high realtime, high reliability for farmland information collection.

(2) For three different frequencies of wireless RF modules, path loss of radio signal is analyzed in different volumetric water content through changing of soil volumetric water content. Experiment shows that soil attenuation is the minimum in the low frequency RF and low volumetric water content.

(3) In $433 \mathrm{MHz}$ RF frequency, path loss is influenced by different depth WUSN node deployed in the soil. The results indicate that signal attenuation is the minimum when node is deployed in suitable depth.

(4) Comparison with manual farmland information acquisition, intelligent water-saving agriculture internet of things based on WUSN improved the real-time of information collection and provide the basis for the application of water-saving agriculture.

\section{Acknowledgements}

The authors wish to thank the National Engineering Research Center for Water-Saving Irrigation, which partially supported this research through the"Twelfth Five-Year" National Science and Technology Support Program" (2011BAD29B08), the 
"Supported by the Programme of Introducing Talents of Discipline to Universities" (B12007) and " China Postdoctoral Science Foundation funded project" . The authors are also grateful to the anonymous reviewers for their valuable feedback.

\section{References}

[1] K. Romer and F. Mattern, "The Design Space of Wireless Sensor networks", IEEE wireless communications, vol. 11, no. 6, (2004), pp. 54-61.

[2] Z. Butler and D. Rus, "Event-based Motion Control for Mobile Sensor Networks", IEEE Pervasive Computing, vol. 2, no. 4, (2003), pp. 34-43.

[3] N. Heo and P. K. Varshney, "A Distributed Self Spreading Algorithm for Mobile Wireless Sensor Networks", Proceedings of IEEE Wireless Communications and Networking Conference, (2003); Louisiana, USA.

[4] I. F. Akyildiz and I. H. Kasimoglu, "Wireless Sensor and Actor Networks: Research Challenges", Ad Hoc Networks, vol. 2, (2004), pp. 351-367.

[5] I. F. Akyildiz and E. P. Stuntebeck, "Wireless underground sensor networks: Research challenges", Ad Hoc Networks, no. 4, (2006), pp. 669-686.

[6] I. F. Akyildiz, M. C. Vuran and Z. Sun, "Channel modeling for Wireless Underground Communication in Soil", Physical Communication, (2009).

[7] I. F. Akyildiz, W. Su, Y. Sankarasubramaniam and E. Cayirci, "Wireless Sensor Networks: A Survey", Computer Networks, vol. 38, no.4, (2002), pp. 393-422.

[8] S. Slijepeevie and M. Potkonjak, "Power Efficient Organization of Wireless Sensor Networks", Proceedings of IEEE Intemational Conference on Communications (ICC), (2001); Helsinki. Finland.

[9] K. Martinez, R. Ong and J. Har, "A Sensor Network for Hostile Environments", IEEE SECON. L, (2004), pp.81-87.

[10] N. Elkmann, H. Althoff, S. Kutzner, T. Stuerze, J. Saenz and B. Reimann, "Development of Fully Automatic Inspection Systems for Large Underground Concrete Pipes Partially Filled with Wastewater", Proceesdings of Robotics and Automation, (2007).

[11] J. F. Mastarone and W. J. Chappell, "Urban Sensor Networking Using Thick Slots in Manhole Covers", Proceedings of Antennas and Propagation Society International Symposium, (2006).

[12] D. J. Daniels, "Surface-Penetrating Radar", Electronics \& Communication Engineering Journal, vol. 8, no. 4, (1996), pp. 165-182.

[13] T. W. Miller, "Effects of Soil Physical Properties on GPR for Landmine Detection", Proceedings of the Fifth International Symposium on Technology and the Mine Problem, (2002).

[14] T. RWeldon and A. Y. Rathore, "Wave Propagation Model and Simulations for Landmine Detection", Tech. rep. Univ. of N. Carolina at Charlotte, (1999).

[15] F. Tashtarian, A. T. Haghighat and M. T. Honary, "A New Energy-Efficient Clustering Algorithm for Wireless Sensor Networks", Telecommunications and Computer Networks, (2007), pp.1-6.

[16] A. Boulis and M. B. Srivastava, "A Framework for Efficient and Programmable Sensor Networks", Proceedings of OPENARCHZ, (2002); New York.

[17] J. Carle and D. S. Ryl, "Energy Efficient Area Monitoring by Sensor Networks", IEEE Computer Magazine, vol. 37, no. 2, (2004), pp.40-46.

[18] O. Younis and S. Fahmy, "HEED: A Hybrid, Energy-Efficient, Distributed Clustering Approach for Ad Hoc Sensor Networks", IEEE Transactions on Mobile Computing, vol. 3, no. 4, (2004), pp.366-379.

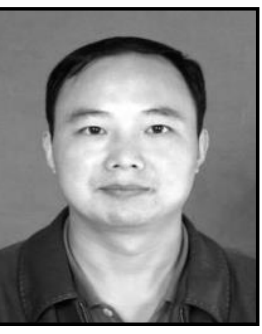

Authors

Zeng L. Zhang, he received his B.S. degree from Department of Mechanical and Electric Engineering, Harbin institute of Technology, Harbin, and M.S. degree from Department of Mechanical and Electric Engineering, Northwest A \& F University, Shaanxi, China in 2000 and 2007, respectively.

Currently, he is a teacher in Department of Mechanical and Electric Engineering, Northwest A \& F University, Shaanxi. He is pursuing $\mathrm{Ph}$.D. degree under the supervision of Prof. Pu T. Wu. His current research interests are in Agricultural Water-Soil Engineering and Wireless Sensor Networks. 

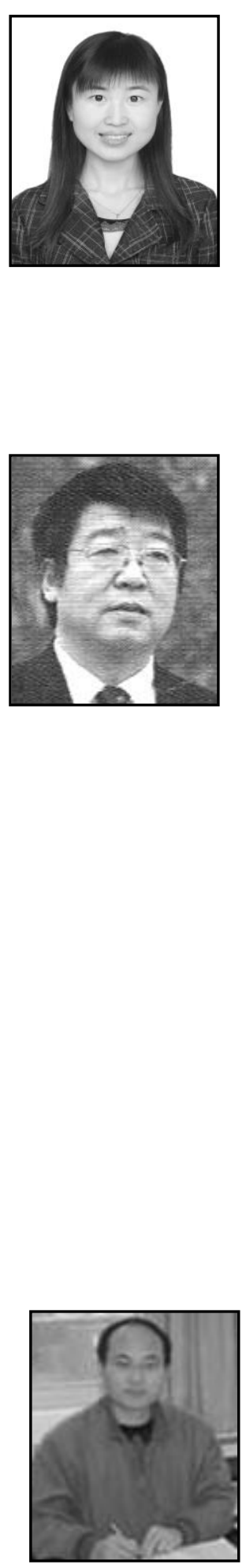

Wen T. Han received his B.S. degree from Department of Mechanical and Electric Engineering, Northwest Agriculture University, Shaanxi, China in 1996. M.S. and Ph.D. degree from Department of Mechanical and Electric Engineering, Northwest A \& F University, Shaanxi, China in 1999 and 2004, respectively.

Working Experiences:

2005-present: researcher, Institute of Soil and Water Conservation of Chinese Academy of Sciences Northwest A \& F University, National Engineering Research Center for Water Saving Irrigation at Yangling.

2004-2005: Assistant Professor, Department of Mechanical and Electric Engineering, Northwest A \& F University.

2001-2004: A lecturer, Department of Mechanical and Electric Engineering, Northwest A \& F University.

Research Interests: 
Information monitoring of crop and environment; Intelligent control for precise irrigation; water distribution Simulation of sprinkler irrigation; Development of nozzle

Currently, he published academic papers more than 30, including SCI and EI articles 16; the national invention patent 6. 
International Journal of Control and Automation Vol. 8, No.4 (2015) 